\title{
Biodegradable Nanocarriers Resembling Extracellular Vesicles Deliver Genetic Material with the Highest Efficiency to Various Cell Types
}

\author{
Yana Tarakanchikova, * Jamal Alzubi, Valentina Pennucci, Marie Follo, Boris Kochergin, \\ Albert Muslimov, Ilya Skovorodkin, Seppo Vainio, Maria N. Antipina, Vsevolod Atkin, \\ Alexey Popov, Igor Meglinski, Toni Cathomen, Tatjana I. Cornu, Dmitry A. Gorin, \\ Gleb B. Sukhorukov, and Irina Nazarenko*
}

Efficient delivery of genetic material to primary cells remains challenging. Here, efficient transfer of genetic material is presented using synthetic biodegradable nanocarriers, resembling extracellular vesicles in their biomechanical properties. This is based on two main technological achievements: generation of soft biodegradable polyelectrolyte capsules in nanosize and efficient application of the nanocapsules for co-transfer of different RNAs to tumor cell lines and primary cells, including hematopoietic progenitor cells and primary $T$ cells. Near to $100 \%$ efficiency is reached using only $2.5 \times 10^{-4}$ pmol of siRNA, and $1 \times 10^{-3} \mathrm{nmol}$ of mRNA per cell, which is several magnitude orders below the amounts reported for any of methods published so far. The data show that biodegradable nanocapsules represent a universal and highly efficient biomimetic platform for the transfer of genetic material with the utmost potential to revolutionize gene transfer technology in vitro and in vivo.
One of the rapidly developing directions of biomedical research and nanotechnology is the design of new delivery systems, in particular, for the delivery of genetic information. Majority of the established immortalized cells lines broadly used by the scientific community allow efficient RNA and DNA transfer using lipid-, polysaccharide-, polymer-, or calcium precipitation-based commercially available reagents. However, manipulation of gene expression in primary cells, including adult and embryonic stem cells and cancer stem cells representing attractive tools for regenerative medicine, cancer therapy, and immune disease treatment, remains still an
Y. Tarakanchikova, B. Kochergin, Dr. I. Nazarenko

Institute for Infection Prevention and Hospital Epidemiology

Medical Center-University of Freiburg

Faculty of Medicine

University of Freiburg

79106 Freiburg, Germany

E-mail:Yana.Tarakanchikova@oulu.fi; irina.nazarenko@uniklinik-freiburg.de

Y. Tarakanchikova, Prof. A. Popov, Prof. I. Meglinski

Opto-Electronics and Measurement Techniques Research Unit

P.O. Box 4500

University of Oulu

Oulu 90014, Finland

Y. Tarakanchikova, A. Muslimov

Nanobiotechnology Laboratory

St. Petersburg Academic University

St. Petersburg 194021, Russia

Y. Tarakanchikova

RASA center in St. Petersburg

Peter the Great St. Petersburg Polytechnic University

St. Petersburg 195251, Russia

The ORCID identification number(s) for the author(s) of this article can be found under https://doi.org/10.1002/smll.201904880.

(C) 2019 The Authors. Published by WILEY-VCH Verlag GmbH \& Co. KGaA, Weinheim. This is an open access article under the terms of the Creative Commons Attribution License, which permits use, distribution and reproduction in any medium, provided the original work is properly cited.

DOI: 10.1002/smll.201904880
Dr. J. Alzubi, Dr. V. Pennucci, Prof. T. Cathomen, Dr. T. I. Cornu Institute for Transfusion Medicine and Gene Therapy

Medical Center - University of Freiburg

Faculty of Medicine

University of Freiburg

79106 Freiburg, Germany

Dr. J. Alzubi, Dr. V. Pennucci, Prof. T. Cathomen, Dr. T. I. Cornu

Center for Chronic Immunodeficiency

Medical Center-University of Freiburg

Faculty of Medicine

University of Freiburg

79106 Freiburg, Germany

Dr. M. Follo

Department of Medicine I

Medical Center-University of Freiburg

Faculty of Medicine

University of Freiburg

Freiburg 153000, Germany

B. Kochergin

Department of Inorganic Chemistry

Ivanovo State University of Chemistry and Technology

Sheremetievskiy Avenue 7, 153000 Ivanovo, Russia

I. Skovorodkin, Prof. S. Vainio

Faculty of Biochemistry and Molecular Medicine

Biocenter Oulu

Laboratory of Developmental Biology

Infotech Oulu

University of Oulu

Borealis Biobank of Northern Finland, 138634 Oulu, Finland 
unsolved challenge. ${ }^{[1,2]}$ Either viral transduction or electroporation-based methods were shown to be most successful regarding transfer efficiency. ${ }^{[3]}$ However, these methods have unwanted side effects hampering translation of in vitro findings to in vivo models. More complexity is expected by translation of this technique to clinical practice, which requires additional features, as the regulated duration of substance release, cost-effectiveness, and biocompatibility. ${ }^{[4]}$

Being a natural communication system between the cells, extracellular vesicles (EV), ${ }^{[5]}$ have great potential as an approach for specific delivery of genetic information. ${ }^{[6]}$ The main advantages of naturally produced EVs compared with other common carriers, e.g., lipid-based nanoparticles, is their high penetration ability, delivery efficiency, and biocompatibility. ${ }^{[7]}$ However, because they possess low loading efficacy, especially for RNA molecules, ${ }^{[8]}$ and because manipulation of naturally produced EVs as well as the production of biomimetic nanovesicles ${ }^{[9]}$ is time- and cost-intensive, alternative carriers sharing the biomechanical properties of natural vesicles and the loading capacity of synthetic carriers can be an attractive alternative.

Polyelectrolyte microcapsules have been developed as a potent drug delivery system. ${ }^{[10]}$ For some applications, porous micron and submicron-sized $\mathrm{CaCO}_{3}$ particles have been used as biocompatible templates with appropriate chemical and mechanical stability, and flexible structural parameters, allowing efficient incorporation of various payloads. ${ }^{[11-15]}$ As a further development, $\mathrm{CaCO}_{3}$ particles have been adopted as a template to produce polyelectrolyte capsules using the Layer-by-Layer (LbL) technique. Being based on electrostatic interactions of charged species positioned on adjacent layers, LbL has an unequaled degree of multifunctionality. ${ }^{[16,17]}$ By application of biocompatible and biodegradable chemicals, biodegradable polyelectrolyte

Dr. M. N. Antipina

Institute of Materials Research and Engineering

$A * S T A R$

Singapore 138634, Singapore

Dr. V. Atkin

Educational Research Institute of Nanostructures and Biosystems

Saratov State University

Saratov, Astrakhanskaya 83, 410012 Saratov, Russia

Prof. I. Meglinski

Aston Institute of Materials Research

School of Engineering and Applied Science

Aston University

Birmingham B4 7ET, UK

Prof. I. Meglinski

School of Life and Health Sciences

Aston University

Birmingham B4 7ET, UK

Prof. D. A. Gorin, Prof. G. B. Sukhorukov

Skoltech center of Photonics \& Quantum Materials

Skolkovo Institute of Science and Technology

Skolkovo Innovation Center

Building 3, Moscow 143026, Russia

Prof. G. B. Sukhorukov

School of Engineering and Material Science

Queen Mary University of London

London B47ET, UK

Dr. I. Nazarenko

German Cancer Consortium (DKTK)

Partner Site Freiburg and German Cancer Research Center (DKFZ)

Heidelberg B47ET, Germany microcapsules have been developed as an attractive carrier for targeting intracellular molecules, ${ }^{[18-21]}$ and have been successfully tested for transfer of drugs and RNA including the incorporation of CRISPR-Cas9 system. ${ }^{[21-25]}$ However, these attractive applications were mainly tested on immortalized cancer cell lines as proof of concept studies. The manipulation of primary and stem cells was not possible by the use of the microcapsules because of their toxicity and low uptake efficiency. ${ }^{[26]}$ Here, we have tested a hypothesis that nanosized carriers might hijack natural intracellular traffic pathways and consequently, transfer with high-efficiency genetic material to any cell type without toxic side-effects. Few works published before, supported this hypothesis, demonstrating proof of concept experiments, e.g., production of PEG LbL-based nanocapsules with paclitaxel or camptothecin core, ${ }^{[27]}$ exhibiting significantly improved activity of camptothecin. ${ }^{[28]}$

First, we develop a new protocol for the production of nanosized $\mathrm{CaCO}_{3}$ core crystals to enrich a decrease of the core size from commonly used 3-5 $\mu \mathrm{m}$ to $300-600 \mathrm{~nm}$ diameter (Figure 1A and Figure S1: Supporting Information). The uptake efficiency, toxicity, capsules degradation, and the efficiency of RNA delivery were then extensively characterized using the HT1080 fibrosarcoma cell line (Figure 1B and Figure S2: Supporting Information). In pursuing our main goal of developing a carrier system mimicking natural extracellular vesicles (EVs) containing functional RNA, ${ }^{[29-34]}$ we compared intracellular localization of EVs and nanocapsules after their uptake. For that, HT1080 cells were treated either with fluorescently labeled EVs or with fluorescently labeled nanocapsules. Confocal microscopy revealed their similar intracellular localization (Figure S2B, Supporting Information). Both were detectable in the perinuclear regions and endocytic compartments supporting our rationale that nanosized capsules will be delivered to the same intracellular compartments as the vesicles, possibly employing their intracellular routes. One can speculate that in contrast to microcapsules internalized mostly by a cholesterol-, and caveolin-dependent pathway ${ }^{[20,21,35-37]}$ and located in the cytoplasm, ${ }^{[38,39]}$ nanocapsules, similar to nanoparticles, due to their smaller size, are internalized via clathrin-mediated endocytosis, ${ }^{[40]}$ which is also one of the main pathways for the internalization of exosomes. ${ }^{[41]}$ However, also other pathways cannot be excluded, like, e.g., direct entry into the cells, due to the positively charged polyarginine moieties binding to with the cell membrane through electrostatic interactions and intensively used for the transfer of quantum dots into the cells. ${ }^{[42]}$ The intracellular traffic routes of nanocapsules in different cell types are not examined yet and will be intensively addressed in future studies. Here we show proof of concept experiments demonstrating their great potential.

We addressed the kinetics of RNA release from the biodegradable nanocapsules. As shown in Figure 1B, $4 \mathrm{~h}$ after treatment, the Rdn-ctrsiRNA-488 capsules were detected within the cells. RdnB (red color) was fully merged with the siRNA-488 (green color), indicating that RNA was still entrapped within the intact capsules (Figure 1B, left panel). The fluorescence signal was increased after $24 \mathrm{~h}$, suggesting that more capsules were internalized. Only a portion of RdnB signal was merged with the siRNA-488 signal, indicating capsule degradation and release of the siRNA-488 from the capsules (Figure 1B, middle panel). A decrease of the fluorescent signal was observed after 
(A)

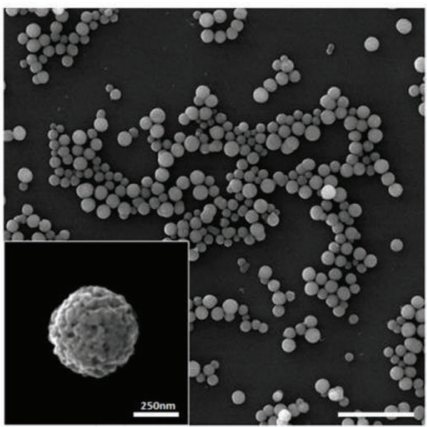

(B)

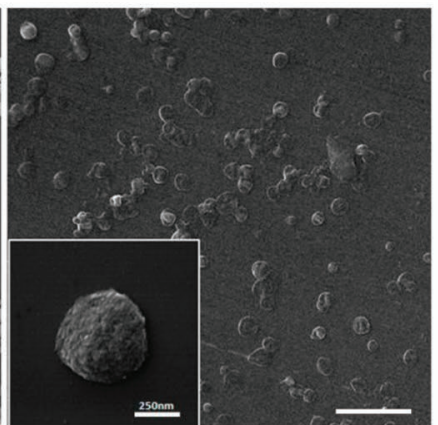

$24 \mathrm{~h}$

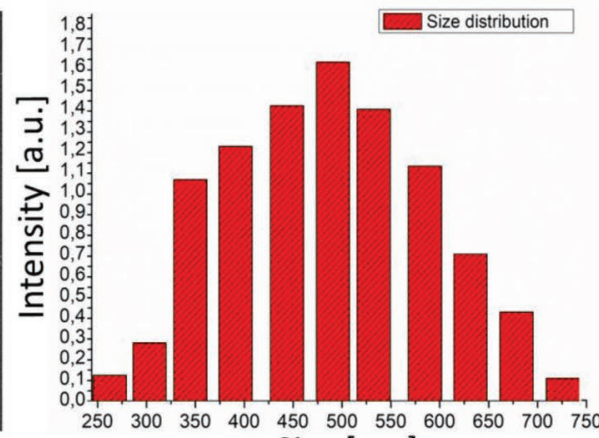

Size $[\mathrm{nm}]$

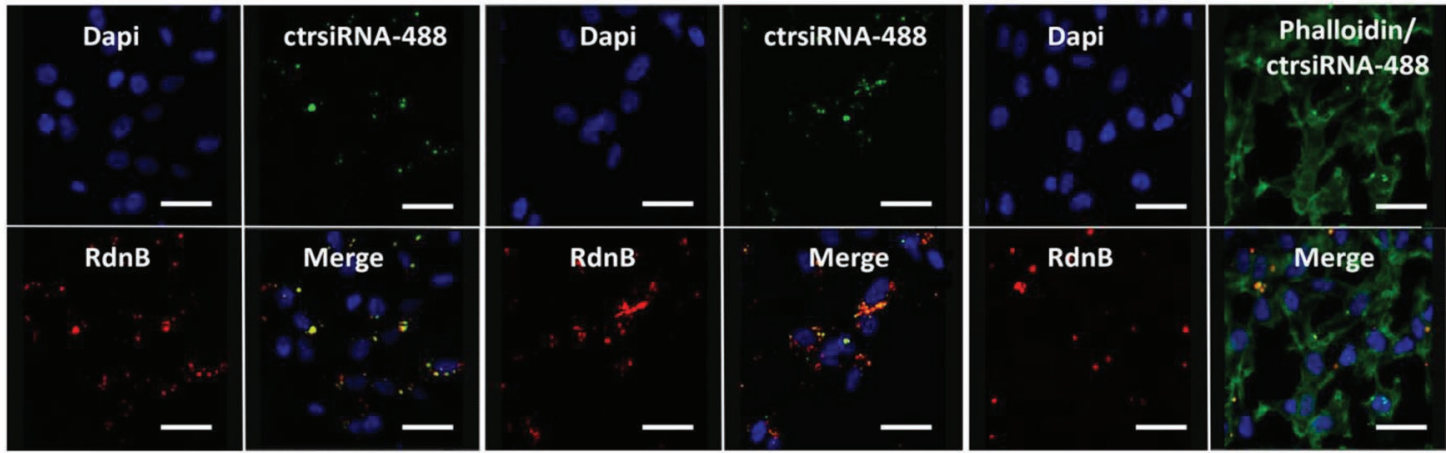

(C)

(D)
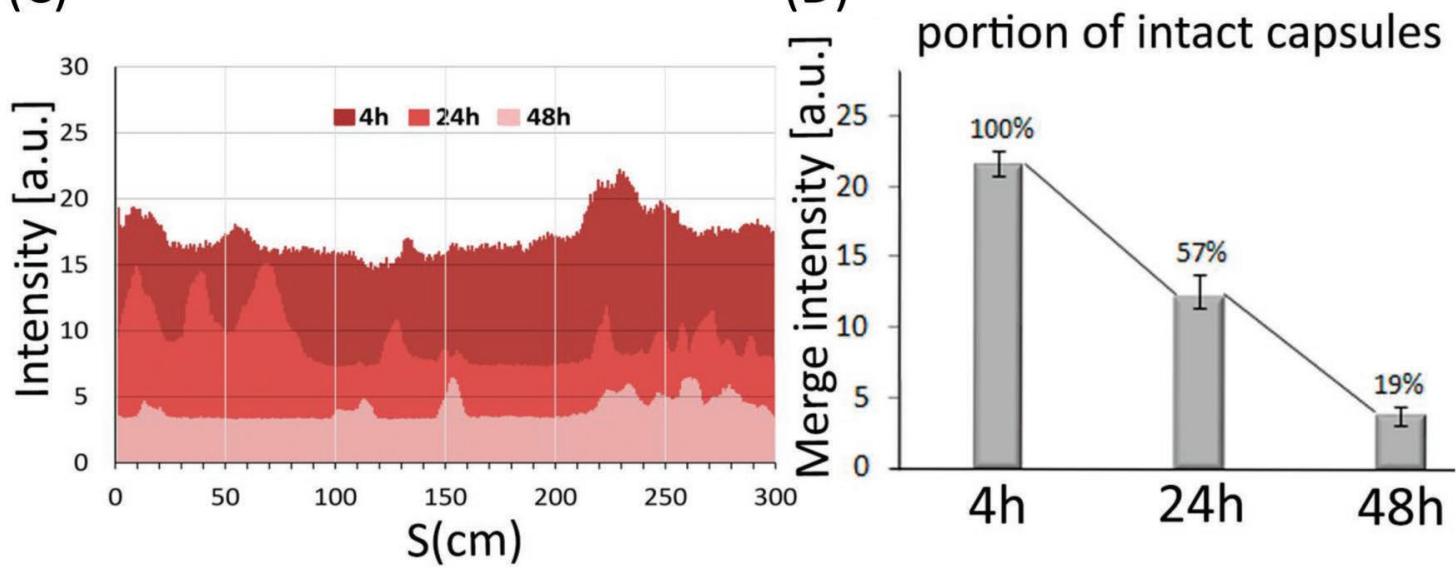

Figure 1. Capsules characterization and determination of efficiency uptake. A) SEM image of a vaterite CaCO 3 particle (left panel) and hollow polymeric capsules (middle panel). Scale bar insert $250 \mathrm{~nm}$, scale image $5 \mu \mathrm{m}$; Nanoparticle tracking analysis showing size distribution of nanocapsules B) Analysis of degradation kinetic of polyelectrolyte nanocapsules. To examine the degradation of capsules within the cells, HT1080 cells were treated with capsules loaded with RdnB and ctrsiRNA-488. Then 4, 24, and $48 \mathrm{~h}$ after treatment, the cells were fixed, stained with phalloidin and DAPI and subjected to confocal microscopy (scale bar $30 \mu \mathrm{m}$ ). C) Quantitative analysis of capsule degradation using Image) (4 h (dark red), $24 \mathrm{~h}$ (red), and $48 \mathrm{~h}$ (light-red)). A dark red diagram indicates the intensity of the yellow signal, showing that majority of capsules is intact; red and light-red diagrams show the intensity of yellow color after 24 and $48 \mathrm{~h}$ respectively, showing a decrease of a number of the intact capsules. D) Diagram, showing a decrease of the intact capsules from $100 \%$ after $4 \mathrm{~h}$ to only $19 \%$ after $48 \mathrm{~h}$.

$48 \mathrm{~h}$ of incubation, suggesting that the majority of capsules degraded. Only a few large red spots, which could represent agglomerated dye, were detected in the cytoplasm partly colocalized with actin filaments or residual RNA (Figure 1B, right panel). Quantitative analysis revealed that about $51 \%$ of the capsules remained intact after $24 \mathrm{~h}$, and about $19 \%$ of the capsules remained intact after $48 \mathrm{~h}$ (Figure 1C,D). This indicates that due to the intracellular proteolytic activity, the majority of the capsules were degraded between 24 and 48 h, allowing the consecutive release of RNA within the cells.

To test the efficiency of our approach, we employed a simple conventional method of knocking down GFP, stably 
overexpressed at a high level in HT1080 cells (Figure S3, Supporting Information). The HT1080-GFP cells were treated with nanocapsules loaded with a control siRNA and GFPspecific siRNA (GFPsiRNA). As a control, the cells were transfected with Lipofectamine 2000 using the same amount of siRNA, corresponding to $2.5 \times 10^{-4} \mathrm{pmol}$ siRNA per cell (Figure S3B, Supporting Information). No residual GFP signal could be detected in the cells treated for $48 \mathrm{~h}$ with the nanocapsules containing GFPsiRNA, in contrast to the cells transfected with GFPsiRNA using Lipofectamine 2000. Quantitative analysis based on calculation of the intensity of the green fluorescence signal revealed $80 \%$ reduction of green fluorescence in the cells treated with nanocapsules filled with GFPsiRNA and only $21 \%$ reduction of GFP signal in the cells transfected with Lipofectamine 2000; no unspecific effects were observed by the application of capsules loaded with the control siRNA (Figure S3, Supporting Information). These results suggest that biodegradable nanocapsules possess utmost high transfer efficiency of RNA molecules with no toxic effect.

Interestingly, by application of biodegradable microcapsules 1-3 $\mu \mathrm{m}$ diameter, to enrich a comparable knockdown efficiency of $80 \%$ in cell lines, 500 pmol/10 capsules/cell siRNA were required, ${ }^{[21]}$ which is $2 \times 10^{6}$ fold more than we used in the current work applying $2.5 \times 10^{-4}$ pmol siRNA/20 capsules/ cell. This comparison argues strongly for unique properties of nanocapsules as highly efficient nucleic acids carriers required several magnitude lower amount of material as microcapsules or any other method reported so far. It is crucial at two points, firstly, because of a smaller risk of potential unspecific off-target effects by the application of nanocapsules required less RNA for the efficient transfer; and secondly, because of considerably lower costs which will be required for scaling-up of the technology and industrial production.

Next, we tested the stability of nanocapsules. Mesenchymal stem cells (MSCs) isolated from the bone marrow were treated with nanocapsules loaded with AllStars Cell Death Control siRNA (apoptsiRNA) containing highly potent validated siRNAs targeting ubiquitous cell survival genes. Additionally, nanocapsules stored for one year at $4{ }^{\circ} \mathrm{C}$ were used. Cell phenotype was controlled after 24 and $48 \mathrm{~h}$ of incubation with capsules (Figure 2A). Quantitative analysis of cell viability revealed 71\% reduction, which is comparable with the effect of Tween-20 used as a positive control for cell death (Figure 2B). Remarkably, capsules stored for one year at $4{ }^{\circ} \mathrm{C}$ showed comparable efficiency, indicating their high stability (Figure 2A, Capsules (1y) panel). Comparable results were received by testing HT1080 cells, showing furthermore increased efficiency of core-free capsules as compared to the capsules, still containing a core (Figure S4, Supporting Information). It is likely that the application of a vaterite core with its subsequent removal provides several advantages as compared to other approaches. Thus, capsules containing hydroxyapatite nanoparticles as a core exhibited a significantly less efficient delivery. ${ }^{[43]}$ Hydroxyapatite is considerably less porous material compared to the vaterite. Possibly, the high porosity of vaterite allows for a more efficient coating of the core nanoparticles with polyarginine molecules. A higher number of positively-charged polyarginine molecules bind a higher number of negatively-charged RNA molecules; consequently, mediating increased loading efficiency. Removal of the vaterite core further improved efficiency. We may speculate that calcium carbonate nanoparticles, one entering the cells, will modulate local intracellular $\mathrm{pH},{ }^{[11]}$ leading to a delay of the degradation of the layers, hampering the release of functional RNA molecules, which would lead to a decrease of delivery efficiency. It is also cannot be excluded that the core-free capsules only, due to the differences in weight, can easier penetrate the cells and escape the lysosomal pathway, allowing for more efficient delivery. Considerable experimental efforts will be required to prove this hypothesis and to learn more about the molecular mechanisms of capsules delivery and their intracellular traffic.

These data demonstrate the utmost high efficiency and stability of biodegradable core-free nanocapsules for the transfer of functional RNA molecules, which is highly relevant given their potential clinical application and GMP requirements.

We tested two further cell types, a breast cancer cell line MDA-MB-361 and primary breast cancer stem-like cells (BCSC), recently characterized elsewhere. ${ }^{[44]}$ Both are highly resistant to any other transfer methods except for viral transduction and electroporation. First, a co-knockdown of two endogenously expressed genes coding for Tspan 8 and E-Cadherin, respectively, was performed using a co-transfer of corresponding siRNAs, which were loaded into the nanocapsules as a mixture. As control a scrambled siRNA was used (Figure 3C). Analysis of knockdown efficiency demonstrated results similar to the efficiency of GFP knockdown observed in the HT1080 cells. No Tspan8- or E-Cadherin specific fluorescent signal could be visualized. Quantification of siRNA effect using RT-PCR revealed up to $90 \%$ signal decrease (Figure S5, Supporting Information).

These data strongly support the universality of nanocapsules able to transfer genetic material with high efficiency to any type of cells, including stem cells, indicating their possible application for in vivo manipulation of cancer and cancer stem cells, inaccessible until now with microcapsules or any of conventional non-viral methods of gene transfer available so far. Also natural vesicles, such as exomes, exhibited considerably lower loading capacity and delivery efficiency of functional siRNA molecules to the cells. ${ }^{[45]}$

To get a step closer toward clinical application, we next tested transfer of nanocapsules into the primary T cells and CD34+ hematopoietic progenitor cells (HPC). Stem cells of hematopoietic origin play key roles in a high number of physiological and pathological processes and their deregulation is linked to a variety of diseases, including HIV, cancer, immune-, autoimmune diseases, and others. Consequently, a technology allowing gene transfer and genome editing of hematopoietic stem cells will open new avenues to conceptual changes in the treatment of previously incurable diseases. ${ }^{[46-48]}$ Among all methods tested so far, viral transduction and electroporation were considered as most efficient and were successfully used. ${ }^{[49,50]}$ However, the viral transfer and nucleofection may result in a considerable portion of cell death and undesired off-target effects. ${ }^{[51]}$ There is a high need for the development of new technologies allowing specific gene delivery to malignant and nonmalignant hematopoietic cells in therapeutic purposes. Due to their small size of $6.8 \mu \mathrm{m}$ average diameter for $\mathrm{T}$ cells ${ }^{[52]}$ and $8.2 \mu \mathrm{m}$ average diameter for the HPCs, ${ }^{[53]}$ they are inaccessible for microcapsule-based transfer. 


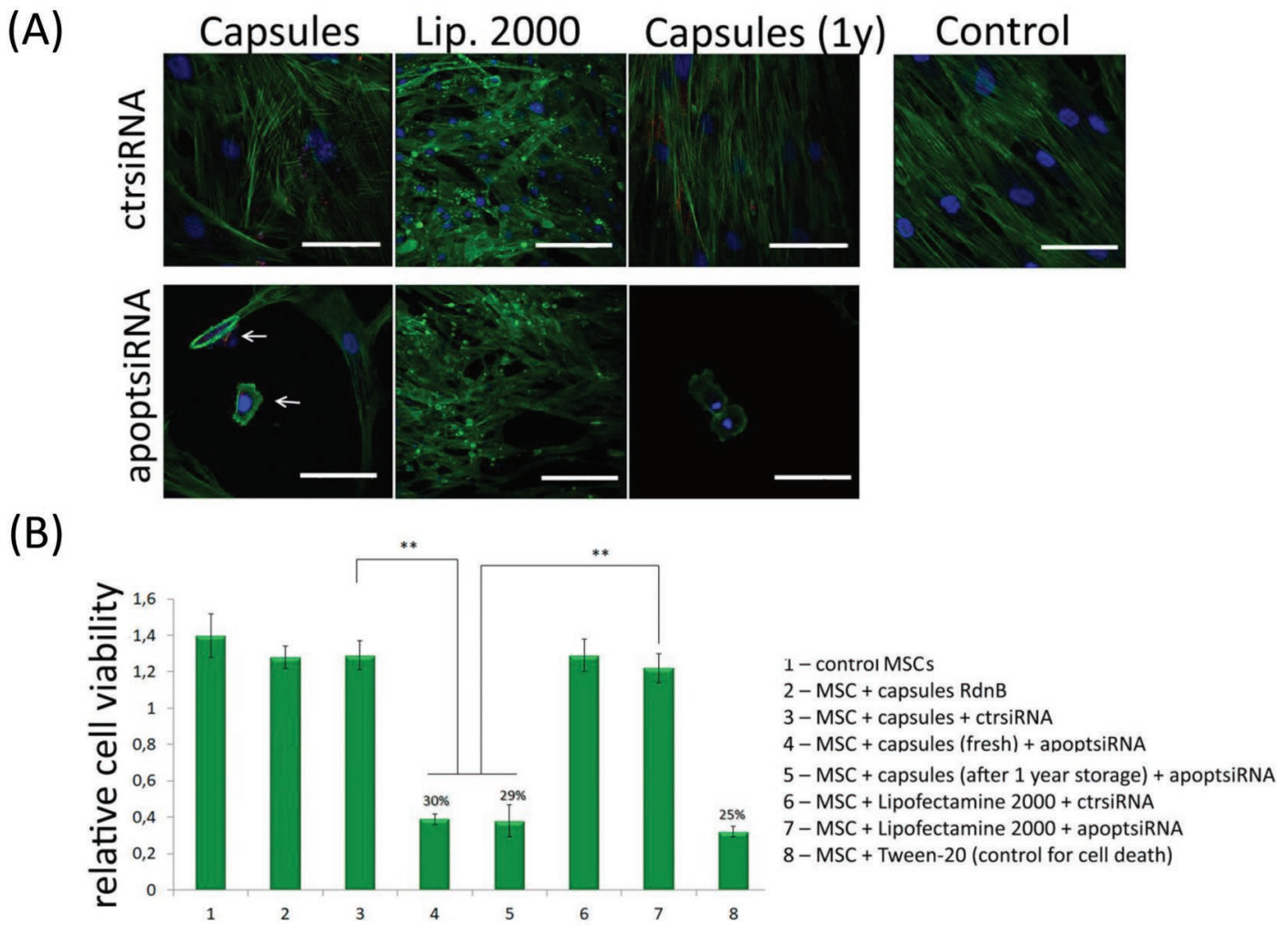

(C)



Cap + ctrsiRNA

Cap + Tspan8siRNA

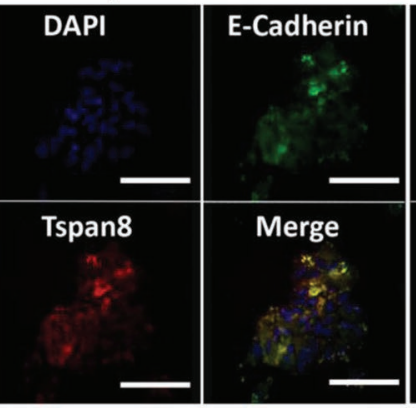

+ E-cadsiRNA
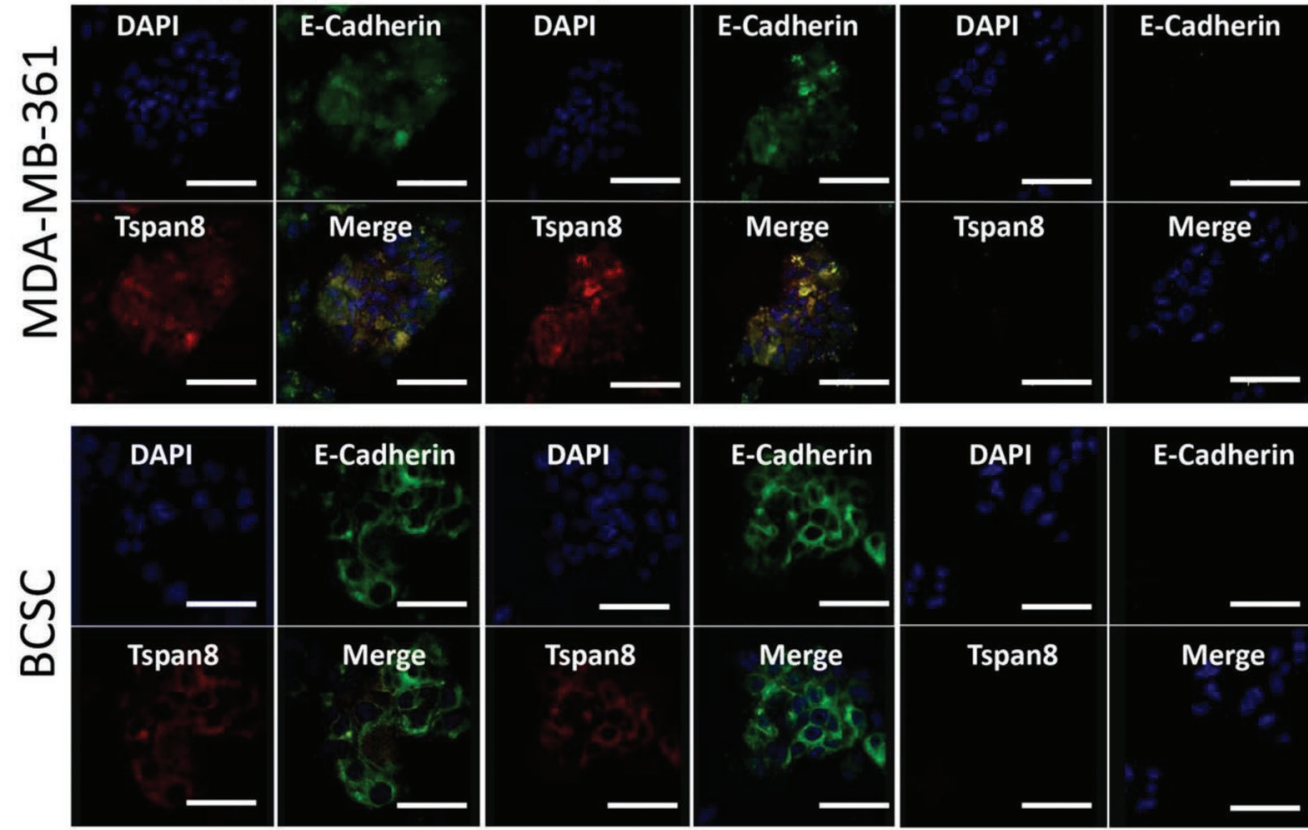

Figure 2. Efficient apoptosis induction in MSCs. A) Confocal images of MSCs treated either with capsules loaded with apoptsiRNA and ctrsiRNA, or transfected with Lipofectamine 2000 using the same amounts of siRNAs. All cells were cultured for $48 \mathrm{~h}$, fixed and stained with phalloidin-Alexa488 and DAPI prior microscopy. To control capsule stability, MSCs were treated with capsules stored for one year. B) The WST-1 assay was performed to quantify cell viability. Reduction of cell number was measured after application of fresh capsules and capsules stored for one-year. No significant reduction of cell viability could be detected in the control. C) Simultaneous loading and transfer of two independent siRNAs for knockdown Tspan8 and E-Cadherin -coding genes in MDA-MB-361 and breast cancer stem-like cells (BCSCs). Scrambled siRNA was used as a control (ctrsiRNA). Complete abolishment of Tspan8-and E-Cadherin specific fluorescent signals was observed after $48 \mathrm{~h}$ of treatment with nanocapsules. 
To adapt nanocapsules to the requirement of gene transfer into HPCs and T cells, we modified the protocol for capsule preparation to produce nanocapsules with an average diameter of $160 \mathrm{~nm}$, ensuring efficient uptake and low toxicity (Figure 3A). To mention is, that application of microcapsules or any capsules larger as reported on hematopoietic stem cells or T cells caused high toxicity. Addressing capsules transfer, we used Rhodamine-labeling as described above.

The analysis of uptake efficiency performed $48 \mathrm{~h}$ posttreatment. For T cells, 10 capsules/cells and for CD34 cells, 5 capsules/cells were considered as an optimal concentration (Figure 3B). Next, we addressed the applicability of nanocapsules for mRNA transfer. First, the transfer of GFP mRNA using $1 \times 10^{-3}$ nmol mRNA per cell was performed and controlled on a single cell level (Figure 3C). Interestingly, in contrast to microcapsules, where the loss of RNA during encapsulation was reported, we did not observe it by the production of nanocapsules. ${ }^{[54]}$

A pilot proof of concept experiment aiming to test the functionality of the transferred mRNA was performed on primary $\mathrm{T}$ cells. The nanocapsules were loaded with Cas9 mRNA and a guide RNA (gRNA) targeting the "HEK site 4" and used for the treatment of primary $\mathrm{T}$ cells. As a positive control, activated $\mathrm{T}$ cells were nucleofected with the same RNA using the 4D nucleofector. Cleaved fragments, indicating nuclease activity, were detected in the sample treated with capsules (cap) containing the CRISPR/Cas9 RNAs and in the nucleofected control (nucl), but not in the untreated samples (UT), thus proving evidence for efficient capsule-mediated RNA delivery into primary $\mathrm{T}$ cells, and supporting their universality (Figure S6, Supporting Information).

Summarizing, our data show that nanocapsules resembling in their size and charge natural extracellular vesicles can universally be applied for transfer of functional RNA molecules to any type of cells with yet unmet efficiency, representing herewith a new unique concept of biomimetic nanotransfer for a broad range of applications in vitro and in vivo.

\section{Experimental Section}

Materials: Anhydrous sodium carbonate, sodium chloride, ethylene glycol, calcium chloride, dextran sulfate sodium salt (DS, MW $>70000$ ), poly-L-arginine hydrochloride (PARG, MW > 70 000), Rhodamine B isothiocyanate (MW 536.08), phosphate buffered saline (PBS, $0.01 \mathrm{M}$ ), calcium chloride dihydrate, ethylenediaminetetraacetic acid disodium salt (EDTA), dimethyl sulfoxide (DMSO), were all obtained from SigmaAldrich. RPMI-1640 medium, fetal bovine serum (FBS), was purchased from Thermo-Fischer Scientific. Control siRNA labeled with Alexa 488 (ctrsiRNA-488) and AllStar Death Control siRNA (apoptsiRNA) were purchased from Qiagen.

Nanocapsules Preparations for the Transfer of RNA in Tumor Cells: The final size of the vaterite particles depends strongly on the concentration of the salts used. ${ }^{\left[{ }^{5}, 56\right]}$ The experience showed that also reaction time and the rotation during mixing are critical. Therefore, a new protocol was developed, allowing to decrease substantially the size of vaterite particles. $1 \mathrm{~mL}$ of $0.33 \mathrm{M} \mathrm{Na}_{2} \mathrm{CO}_{3}$ and $1 \mathrm{~mL}$ of $0.33 \mathrm{M}$ $\mathrm{CaCl}_{2}$ were dissolved in $10 \mathrm{~mL}$ ethylene glycol (EG) and rapidly mixed under magnetic stirring for $3 \mathrm{~h}$. After $3 \mathrm{~h}$ of stirring, the particles were sediment by centrifugation, resuspended in $1 \mathrm{~mL}$ of $\mathrm{ddH}_{2} \mathrm{O}$ and stored at $4{ }^{\circ} \mathrm{C}$ until further use. The size of $\mathrm{CaCO}_{3}$ particles obtained was in the range of $300-600 \mathrm{~nm}$
Nanocapsules Preparations for the Transfer of RNA in Primary Cells: For RNA transfer into the human CD34 hematopoietic stem cells and primary $T$ cells smaller capsules were produced. For that, a new protocol was developed for the preparation of $\mathrm{CaCO}_{3}$ nanoparticles. Firstly, gelatin $(3 \mathrm{~g})$ was dissolved in $\mathrm{ddH}_{2} \mathrm{O}(50 \mathrm{~mL})$ and heated to $90{ }^{\circ} \mathrm{C}$. After that, the gelatin solution was rapidly mixed upon magnetic stirring with $99 \%$ Glycerol $(50 \mathrm{~mL})$. Taking into account that the size of valerate crystals is strictly dependent on salt concentration, ${ }^{[56]} 0.1 \mathrm{M} \mathrm{Na}_{2} \mathrm{CO}_{3}$ $(10 \mathrm{~mL})$ and $0.1 \mathrm{M} \mathrm{CaCl} 2(10 \mathrm{~mL})$ were mixed as stirred for $24 \mathrm{~h}$. The fabricated particles were sediment by ultracentrifugation at $40000 \times \mathrm{g}$ and washed with hot water $\left(70{ }^{\circ} \mathrm{C}\right)$. After that, nanoparticles of $\mathrm{CaCO}_{3}$ were covered by polymers (PARG/DS) 2 .

RNA and Dye Encapsulation: Encapsulation of a dye was developed using the layer-by-layer (LbL) technique. The $\mathrm{LbL}$ technique is based on the sequential adsorption of oppositely charged molecules, such as polyelectrolytes, onto a charged sacrificial template. For the layers, biocompatible polyelectrolytes Dextran Sulfate (DS) $1 \mathrm{mg} \mathrm{mL}^{-1}(2 \mathrm{~mL})$ and poly-L-arginine hydrochloride (PARG) $1 \mathrm{mg} \mathrm{mL}^{-1}(1 \mathrm{~mL})$ were applied. For the preparation of labeled capsules, rhodamine isocyanate (concentration $1 \mathrm{mg} \mathrm{mL}^{-1}$ ) was added as a first layer to $\mathrm{CaCO}_{3}$ particles diluted in $2 \mathrm{~mL}$ of $\mathrm{ddH}_{2} \mathrm{O}$ which was conjugated with polymer PARG. Then 2 layers of DS and PARG were coated consequently. For the encapsulation of RNA, a new method was developed. First, $50 \mu \mathrm{L}$ of the $20 \mathrm{pmol}$ siRNA solution was diluted in $1 \mathrm{~mL}$ RNase-free, DNasefree $\mathrm{ddH}_{2} \mathrm{O}$. If 2 different siRNAs were applied, a 1:1 mixture was prepared. If mRNA was encapsulated, 1-5 $\mu \mathrm{g}$ mRNA in the presence of RNase inhibitor was used. The RNA layers were coated on the PARG layer and covered again with a PARG layer. It is important that the last layer has a positive charge. Next, the core was removed with ethylenediaminetetraacetic acid (EDTA); capsules were resuspended in $1 \mathrm{~mL} \mathrm{ddH} \mathrm{H}_{2} \mathrm{O}$ and final concentration $8 \times 10^{8} \mathrm{~mL}^{-1}$.

siRNA and mRNA Transfer by Capsules and Transfection: One day before transfection or treatment with capsules, tumor cells and MCSs were seeded in 4-well or 8-well chamber slides (Ibidi) using $2 \times 10^{4}$ cells in $300 \mu \mathrm{L}$ of cell culture medium per well and grown overnight to the expected cell density of $60-70 \%$. Capsules were added at concentration of 20 capsules per cell and incubated for the desired duration. For transfection Lipofectamine 2000 was used; transfection was performed according to the recommendation of the supplier. Cells were transfected with an amount of siRNA, corresponding to the amount of siRNA loaded in the capsules. Thus, $1,6 \times 10^{6}$ capsules and 20 pmol siRNA were used for $8 \times 10^{4}$ cells for treatment or transfection respectively.

Scanning Electron Microscopy (SEM): Capsule morphologies were examined using scanning electron microscopy (SEM MIRA II LMU (TESCAN). Capsule suspension was dropped to the silicon surface, dried, coated with gold. SEM observation was carried out using an accelerating voltage of $10 \mathrm{kV}$. To visualize cells uptake and evaluate capsules, a confocal laser microscopy system was used.

Transmission Electron Microscopy (TEM): TEM was used to control the quality of EV preparations and their integrity. $10 \mu \mathrm{L}$ of the vesicle preparation was loaded on a 300-mesh copper grid and fixed with $1 \%$ glutaraldehyde. Next, they were washed with double distilled water and negatively stained with $10 \mu \mathrm{L}$ drop of $1 \%$ uranyl acetate and washed. Images were taken by the electron microscope (LEO 906 E, Zeiss, Oberkochen, Germany) using SIS software (Olympus, Hamburg, Germany).

Cell Lines and Primary Cells: Fibrosarcoma cell line HT1080 was purchased from the ATCC Cell culture collection and maintained in $\mathrm{RPMI}+10 \% \mathrm{FBS}$ at $37{ }^{\circ} \mathrm{C}$ and $5 \% \mathrm{CO}_{2}$. MSCs were kindly provided by Bernd Giebel (Essen University Clinic, Essen Germany), BMSCs were kindly provided by Jochen Mauer (University Clinic Aachen, Aachen, Germany). Peripheral blood mononuclear cells (PBMCs) were isolated using phase separation and then frozen in liquid nitrogen until used. PBMCs were thawed and recovered for $24 \mathrm{~h}$ in RPMI complete medium supplemented with $10 \%$ fetal calf serum, penicillin $\left(100 \mathrm{U} \mathrm{mL}^{-1}\right)$, streptomycin $\left(100 \mathrm{mg} \mathrm{L}^{-1}\right)$ and HEPES $\left(10 \times 10^{-3} \mathrm{M}\right)$. Then, T cells were activated using anti-CD2/CD3/CD2 antibodies (ImmunoCult, Stem Cell technology) and cultured with RPMI complete medium supplemented 
(A)
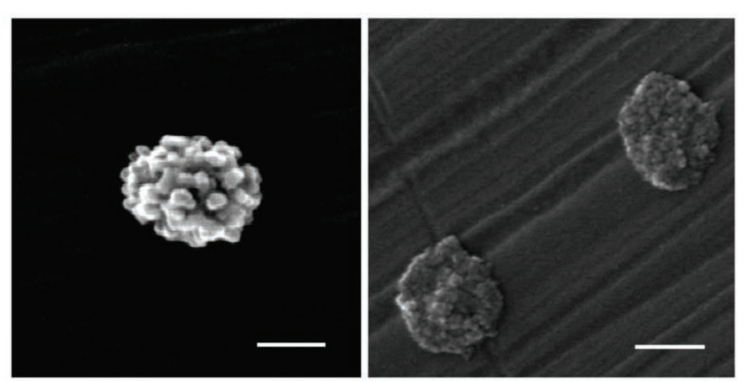

(B)

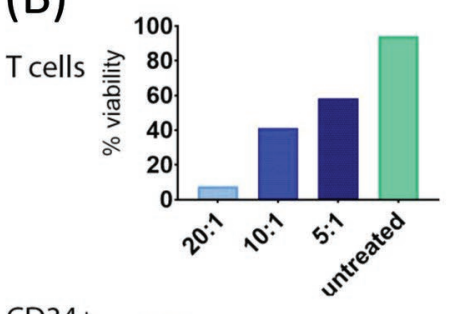

CD34+
cells

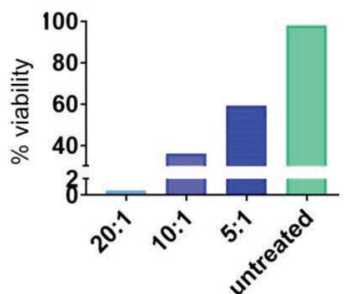

(C)

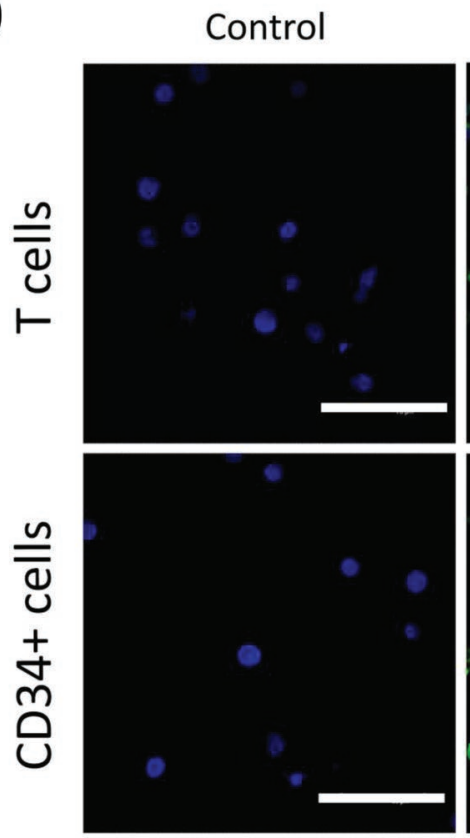

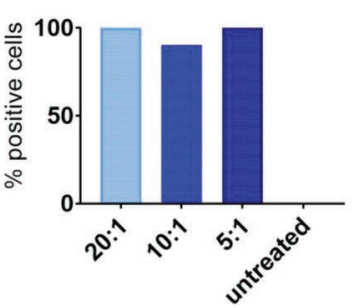

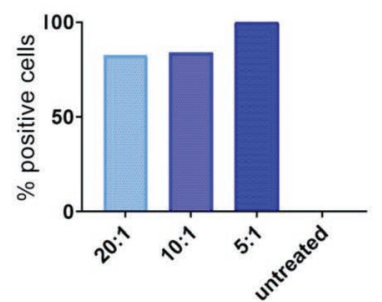

Cap. + mRNA GFP
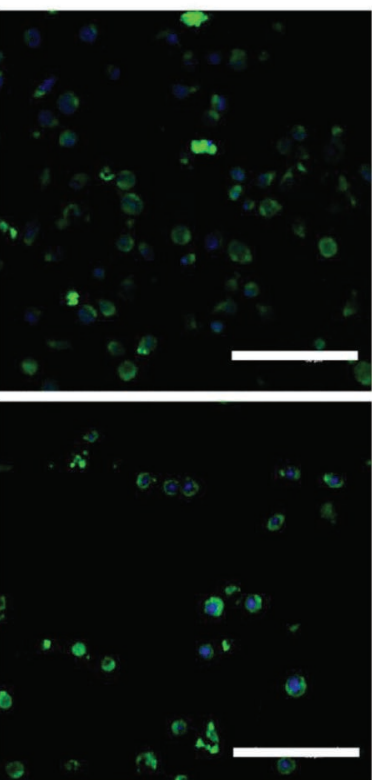

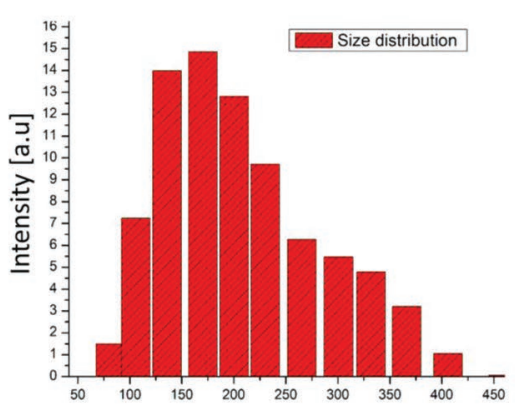

Size $[\mathrm{nm}]$
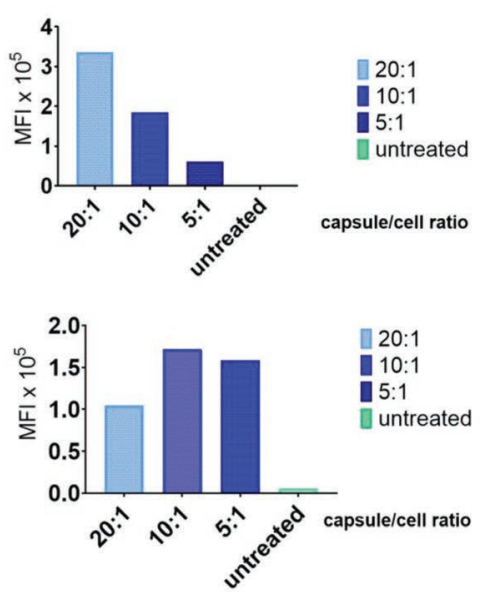

Cap. + mRNA

GFP (single cell)
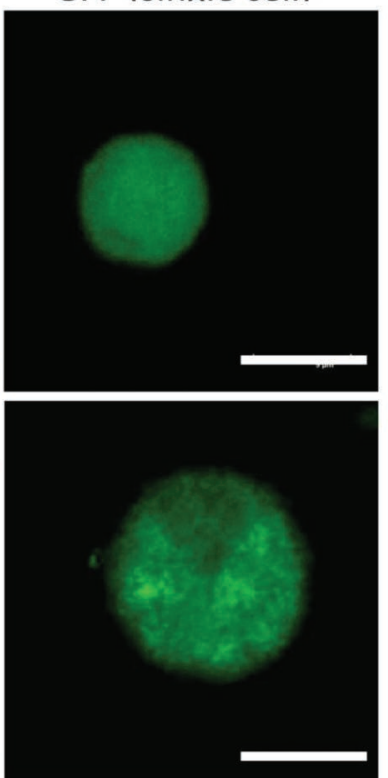

Figure 3. Nanocapsules developed for the transfer of genetic material to primary T cells and hematopoietic stem cells. A) Scanning electron microscopy of the $\mathrm{CaCO} 3$ core (left panel), and ready-to-use capsules (middle panel). Scale bar $100 \mathrm{~nm}$. Nanoparticle tracking analysis shows the size distribution between 50 and $280 \mathrm{~nm}$ with a peak of $160 \mathrm{~nm}$ (right panel). B) Flow cytometry analysis of T cells (upper panels) and CD34+ (bottom panels) cells treated with Rhodamine-labeled nanocapsules showed that application of 5 nanocapsules/cells is sufficient for an efficient transfer of capsules into CD34+ cells, and 10 nanocapsules/cell is sufficient for an efficient transfer of capsules into T cells. Application of higher nanocapsules number led to the reduction of cell viability (left panel). C) Confocal microscopy of T cells and CD34+ cells revealed efficient transfer of GFP mRNA. Images were taken $72 \mathrm{~h}$ post-treatment with capsules. Cells were stained with DAPI to visualized cell nuclei. Green fluorescence show cells expressing GFP after uptake of nanocapsules. Scale bar left panel $30 \mu \mathrm{m}$, right panel $9 \mu \mathrm{m}$. 
with $100 \mathrm{U} \mathrm{mL}^{-1} \mathrm{IL}-2,25 \mathrm{U} \mathrm{mL}^{-1}$ IL-7, and $50 \mathrm{U} \mathrm{mL} \mathrm{mL}^{-1} \mathrm{IL}-15$ for 3 days before transfection. Cord blood CD34+ cells were purchased from Lonza. After thawing, cells were cultivated in GMP SCGM media (Cellgenix) supplemented with $60 \mathrm{ng} \mathrm{mL}^{-1} \mathrm{SCF}, 60 \mathrm{ng} \mathrm{mL}^{-1} \mathrm{Flt} 3 \mathrm{~L}$, $20 \mathrm{ng} \mathrm{mL}^{-1} \mathrm{TPO}, 20 \mathrm{ng} \mathrm{mL}^{-1}$ IL3 (all from Immunotools), penicillin $\left(100 \mathrm{U} \mathrm{mL} \mathrm{m}^{-1}\right)$, streptomycin $\left(100 \mathrm{mg} \mathrm{L}^{-1}\right)$. At day $3,1 \times 10^{6}$ activated T cells or $7.5 \times 10^{4} \mathrm{CD} 34+$ cells were transfected with nanocapsules loaded with Rhodamine, in order to define the concentration of capsules allowing maximal uptake by minimal toxicity. All human experiments were performed in accordance with the Declaration of Helsinki. All patients involved provided written informed consent. The experimental protocols were approved by the institutional review board vote $307 / 13$ independent Ethics Committee of the University of Freiburg.

Viability Assay: To measure cytotoxicity and viability, WST-1 assay was performed according to the manufacturers' recommendations. Briefly, cells were seeded in a 96-well plate and incubated overnight. After administration of capsules loaded with corresponding siRNAs or treated with Tween-20 used as a positive control for cell death, cells were cultured for 24,48 , or $72 \mathrm{~h}$, respectively as required. WST1 reagent was added to each well and maintained for $4 \mathrm{~h}$. The absorbance at $450 \mathrm{~nm}$ was monitored using TECAN Elisa Reader and the reference wavelength was set at $630 \mathrm{~nm}$. The relative cell viability percentage in each group was calculated by comparison to that of the control group.

Immunofluorescence: Two days before the experiment, $1.5 \times 10^{4}$ cells per well were seeded in the ibidi 8 -well $\mu$-slide chamber. On the day of staining, cells were fixed with $4 \%$ paraformaldehyde for 5 min at $37^{\circ} \mathrm{C}$ washed and permeabilized with $0.1 \%$ Triton-X 100 . For staining, cytoskeleton phalloidin conjugated with either Alexa488 or Alexa594 fluorophores was applied for $1 \mathrm{~h}$ and washed. Next, the nuclei were stained with DAPI for $20 \mathrm{~min}$ at room temperature, washed and incubated with Prolong Diamond anti-fade mountant, allowed to heal overnight at room temperature. Images were taken using a Leica confocal microscope (Leica TCS SP2 AOBS) equipped with an HCX PL APO 63× NA 1.4 oil immersion objective. Images for the different fluorophores were scanned sequentially. Further image processing was carried out using Image).

Image Analysis: For quantitative evaluation of green signal intensity, Imagel was used. The experiment was done in biological triplicates. For statistical analysis, five images of each delivery method were taken. For each image, the intensity distribution graph of the green signal over the area was plotted. Area statistics were calculated for the complete image and the average intensity value was calculated.

Flow Cytometry: To test the viability of T cells and CD34+ cells and the efficiency of capsule transfer, FACS analysis was performed using BD Accuri (BD Biosciences, NY, USA). Percentages of dead and apoptotic cells were measured by staining with 7-AAD (PanReac Applichem) stains following the manufacturers' instructions. Cells treated with capsules for 48-72 $\mathrm{h}$ were washed with $1 \mathrm{~mL}$ PBS and recovered by centrifugation at $300 \times g$ for $5 \mathrm{~min}$. Cell pellets were resuspended in $500 \mu \mathrm{L}$ cold PBS, divided into two flow cytometry tubes for stained and unstained readout, and a minimum of $10^{4}$ cellular events was recorded. Data analysis was performed with BD Accuri C6 Software (BD Biosciences, NY, USA), GraphPad Prism was used for statistics.

EV Isolation: For isolation of small EVs, cells were maintained under starvation conditions for $36 \mathrm{~h}$. The harvested medium was centrifuged for $15 \mathrm{~min}$ at $2000 \times \mathrm{g}$, followed by $45 \mathrm{~min}$ at $5000 \times \mathrm{g}$ and $30 \mathrm{~min}$ at $12000 \times g$. The supernatant was filtered with a $0.2 \mu \mathrm{m}$ membrane and concentrated in a concentration chamber to achieve a volume of 30 to $50 \mathrm{~mL}$. This concentrated supernatant was centrifuged at $120000 \times \mathrm{g}$ for $1.5 \mathrm{~h}$. The resulting supernatant was discarded and the exosome pellet washed with $11.5 \mathrm{~mL}$ sodium chloride, followed by a second centrifugation step at $120000 \times g$ for $2 \mathrm{~h}$. The supernatant was discarded and the exosome pellet resuspended with sodium chloride with a final volume of $200 \mu \mathrm{L}$ per cell line.

Staining of Vesicles with PKH26: To produce fluorescent vesicles, HT1080 parental cells were stained with the PKH26 dye according to the recommendations of the supplier. Afterward, cells were washed and maintained for $36 \mathrm{~h}$ in the serum-free medium upon starvation. Conditions medium was used to isolate EVs according to the general protocol.
Nanoparticle Tracking Analysis: Exosome and Capsule concentration and size distribution were analyzed by nanoparticle tracking analysis (NTA) using the ZetaView system PMX110 (Particle Metrix, Meerbusch, Germany) according to the manufacturer's instructions. Briefly, samples were diluted in filter-sterilized HEPES buffers; using ration 1:500 for exosomes and 1:100 for capsules. Images were recorded at 11 positions and five cycles with camera sensitivity $95 \%$; shutter position 70 ; the temperature was monitored manually, ranged from 21 to $22^{\circ} \mathrm{C}$.

$m R N A$ Loading: The same capsulation procedure was used for mRNA loading. mRNA was diluted in $100 \mu \mathrm{L}$ of RNase free water. Capsules with structure (PARG/DS) $)_{2}$ in $100 \mu \mathrm{L}$ from capsules stock solution was added to mRNA solution together with the RNase inhibitor. Solution capsules + mRNA was gently stirred for 30 min.

mRNA Transfer: One day before treatment with capsules, cells were seeded in 8-well chamber slides (Ibidi). $5 \times 10^{9}$ capsules were used for the treatment of $1 \times 10^{6} \mathrm{~T}$ cells; $2.5 \times 10^{9}$ capsules were used for the treatment of $7.5 \times 10^{4} \mathrm{CD} 34+$ cells. After $48 \mathrm{~h}$, cells were examined by flow cytometry and confocal microscopy. To test the applicability of nanocapsules to edit primary $T$ cells, the cells were isolated as described above; the nanocapsules were loaded with Cas 9 mRNA and a guide RNA (gRNA) targeting the "HEK site 4" genomic locus. ${ }^{[57]}$ As a positive control, $1 \times 10^{6}$ activated T cells were nucleofected with $5 \mu \mathrm{g}$ of mRNA encoding Cas 9 and 75 pmol of gRNA targeting the "HEK site 4" locus using the 4D nucleofector according to the manufacturer recommendation (Lonza, P3 kit, EO-115 program). After transfer of capsules or nucleofection, respectively, T cells were recovered in 96-well plates for four days before assessing the nuclease cleavage activity at the target locus. The activity of the nuclease was controlled by measuring the extent of non-homologous end joining (NHEJ)-mediated mutagenic repair at the target site using the mismatch-sensitive T7 endonuclease 1 (T7E1) assay. At day four post-transfection, cells were harvested and genomic DNA was extracted using direct lysis buffer mixed with proteinase $\mathrm{K}\left(20 \mathrm{mg} \mathrm{mL} \mathrm{m}^{-1}\right)$. An amplicon encompassing the nuclease target site in the "HEK site 4" locus was generated by PCR using the primer pair (5'-AGGCAGAGAGGGGTTAAGGT-3' and $5^{\prime}$-GGGTCAGACGTCCAAAACCA-3'). Afterward, amplicons were purified using QIAquick PCR Purification Kit and subjected to digestion with T7E1 as previously described. ${ }^{[58]}$ Cleaved fragments are an indication for the activity of the nuclease at the intended target site compared to the un-transfected (UT) sample were no cleaved fragments can be observed.

\section{Supporting Information}

Supporting Information is available from the Wiley Online Library or from the author.

\section{Acknowledgements}

G.B.S. and I.N. contributed equally to this work. The work was supported by BMBF IB-GUS/RUS 01DJ15026 and ERA-RusPlus/ID110 Exodiagnos/BMWi ZIM collaboration project KF2979902CR4 to IN; by Government of the Russian Federation (Grant No 14.Z50.31.0004 to support scientific research projects implemented under the supervision of leading scientists at Russian institutions and Russian institutions of higher education) to G.B.S. and D.A.G., Y.T., V.A. The authors acknowledge e-cost Actions COST-BM2012-MEHAD and COST-BM1401-Raman4Clinics. A special thanks to Bernd Giebel for providing MCSs, Jochen Mauer and Juliane Strietz for providing BCSCs, Tanja Gainey-Schleicher and Maren Voglstaetter for technical support and to Deborah Lawrie-Blum for proof-reading the manuscript.

\section{Conflict of Interest}

Toni Cathomen and Tatjana I. Cornu. have a sponsored research collaboration with Cellectis S.A. Toni Cathomen is a consultant to TRACR Hematology. 


\section{Keywords}

biomimetics, drug delivery, extracellular vesicles, gene delivery, microcapsules, nanocapsules

Received: August 28, 2019

Revised: October 31, 2019

Published online: December 16, 2019

[1] Y. F. Zhou, M. Bosch-Marce, H. Okuyama, B. Krishnamachary, H. Kimura, L. Zhang, D. L. Huso, G. L. Semenza, Cancer Res. 2006, 66, 10849.

[2] V. Mundra, I. C. Gerling, R. I. Mahato, Mol. Pharmaceutics 2013, 10, 77.

[3] Y. Diener, A. Bosio, U. Bissels, Exp. Hematol. 2016, 44, 991.

[4] S. Swain, P. K. Sahu, S. Beg, S. M. Babu, Curr. Drug Delivery 2016, $13,1290$.

[5] G. Raposo, W. Stoorvogel, J. Cell Biol. 2013, 200, 373.

[6] S. Fais, L. O'Driscoll, F. E. Borras, E. Buzas, G. Camussi, F. Cappello, J. Carvalho, A. Cordeiro da Silva, H. Del Portillo, S. El Andaloussi, T. Ficko Trcek, R. Furlan, A. Hendrix, I. Gursel, V. Kralj-Iglic, B. Kaeffer, M. Kosanovic, M. E. Lekka, G. Lipps, M. Logozzi, A. Marcilla, M. Sammar, A. Llorente, I. Nazarenko, C. Oliveira, G. Pocsfalvi, L. Rajendran, G. Raposo, E. Rohde, P. Siljander, G. van Niel, M. H. Vasconcelos, M. Yanez-Mo, M. L. Yliperttula, N. Zarovni, A. B. Zavec, B. Giebel, ACS Nano 2016, 10, 3886.

[7] T. Lener, M. Gimona, L. Aigner, V. Borger, E. Buzas, G. Camussi, N. Chaput, D. Chatterjee, F. A. Court, H. A. Del Portillo, L. O'Driscoll, S. Fais, J. M. Falcon-Perez, U. Felderhoff-Mueser, L. Fraile, Y. S. Gho, A. Gorgens, R. C. Gupta, A. Hendrix, D. M. Hermann, A. F. Hill, F. Hochberg, P. A. Horn, D. de Kleijn, L. Kordelas, B. W. Kramer, E. M. Kramer-Albers, S. Laner-Plamberger, S. Laitinen, T. Leonardi, M. J. Lorenowicz, S. K. Lim, J. Lotvall, C. A. Maguire, A. Marcilla, I. Nazarenko, T. Ochiya, T. Patel, S. Pedersen, G. Pocsfalvi, S. Pluchino, P. Quesenberry, I. G. Reischl, F. J. Rivera, R. Sanzenbacher, K. Schallmoser, I. Slaper-Cortenbach, D. Strunk, T. Tonn, P. Vader, B. W. van Balkom, M. Wauben, S. E. Andaloussi, C. Thery, E. Rohde, B. Giebel, J. Extracell. Vesicles 2015, 4, 30087.

[8] S. A. Kooijmans, S. Stremersch, K. Braeckmans, S. C. de Smedt, A. Hendrix, M. J. Wood, R. M. Schiffelers, K. Raemdonck, P. Vader, J. Controlled Release 2013, 172, 229.

[9] T. R. Lunavat, S. C. Jang, L. Nilsson, H. T. Park, G. Repiska, C. Lasser, J. A. Nilsson, Y. S. Gho, J. Lotvall, Biomaterials 2016, 102, 231.

[10] A. D. Kulkarni, Y. H. Vanjari, K. H. Sancheti, H. M. Patel, V. S. Belgamwar, S. J. Surana, C. V. Pardeshi, Artif. Cells, Nanomed., Biotechnol. 2016, 44, 1615.

[11] D. V. Volodkin, A. I. Petrov, M. Prevot, G. B. Sukhorukov, Langmuir 2004, 20, 3398.

[12] J. J. Richardson, J. W. Maina, H. Ejima, M. Hu, J. Guo, M. Y. Choy, S. T. Gunawan, L. Lybaert, C. E. Hagemeyer, B. G. De Geest, F. Caruso, Adv. Sci. 2015, 2, 1400007.

[13] Y. Svenskaya, B. Parakhonskiy, A. Haase, V. Atkin, E. Lukyanets, D. Gorin, R. Antolini, Biophys. Chem. 2013, 182, 11.

[14] D. Horn, J. Rieger, Angew. Chem., Int. Ed. 2001, 40, 4330.

[15] D. V. Volodkin, N. I. Larionova, G. B. Sukhorukov, Biomacromolecules 2004, 5, 1962.

[16] M. L. De Temmerman, J. Demeester, F. De Vos, S. C. De Smedt, Biomacromolecules 2011, 12, 1283.

[17] I. L. Radtchenko, G. B. Sukhorukov, S. Leporatti, G. B. Khomutov, E. Donath, H. Mohwald, J. Colloid Interface Sci. 2000, 230, 272.

[18] B. Packman, E. Packman, G. Doyle, S. Cooper, E. Ashraf, K. Koronkiewicz, S. Jayawardena, Headache 2000, 40, 561.
[19] F. Caruso, R. A. Caruso, H. Mohwald, Science 1998, 282, 1111.

[20] B. G. De Geest, N. N. Sanders, G. B. Sukhorukov, J. Demeester, S. C. De Smedt, Chem. Soc. Rev. 2007, 36, 636.

[21] A. S. Timin, A. R. Muslimov, A. V. Petrova, K. V. Lepik, M. V. Okilova, A. V. Vasin, B. V. Afanasyev, G. B. Sukhorukov, Sci. Rep. 2017, 7, 102.

[22] H. Gao, O. A. Goriacheva, N. V. Tarakina, G. B. Sukhorukov, ACS Appl. Mater. Interfaces 2016, 8, 9651.

[23] C. Ganas, A. Weiss, M. Nazarenus, S. Rosler, T. Kissel, P. Rivera Gil, W. J. Parak, J. Controlled Release 2014, 196, 132.

[24] Y. I. Svenskaya, A. M. Pavlov, D. A. Gorin, D. J. Gould, B. V. Parakhonskiy, G. B. Sukhorukov, Colloids Surf., B 2016, 146, 171.

[25] A. S. Timin, A. R. Muslimov, K. V. Lepik, O. S. Epifanovskaya, A. I. Shakirova, U. Mock, K. Riecken, M. V. Okilova, V. S. Sergeev, B. V. Afanasyev, B. Fehse, G. B. Sukhorukov, Nanomedicine 2018, $14,97$.

[26] C. Sanz-Nogues, J. Horan, K. Thompson, L. Howard, G. Ryan, M. Kassem, T. O'Brien, J. Biomed. Mater. Res., Part A 2015, 103, 3676.

[27] T. G. Shutava, P. P. Pattekari, K. A. Arapov, V. P. Torchilin, Y. M. Lvov, Soft Matter 2012, 8, 9418.

[28] G. Parekh, P. Pattekari, C. Joshi, T. Shutava, M. DeCoster, T. Levchenko, V. Torchilin, Y. Lvov, Int. J. Pharm. 2014, 465, 218.

[29] M. Varela-Eirin, A. Varela-Vazquez, M. Rodriguez-Candela Mateos, A. Vila-Sanjurjo, E. Fonseca, J. L. Mascarenas, M. Eugenio Vazquez, M. D. Mayan, Biochim. Biophys. Acta, Mol. Cell Res. 2017, 1864, 728.

[30] J. Lotvall, H. Valadi, Cell Adhes. Migr. 2007, 1, 156.

[31] A. J. O'Loughlin, I. Mager, O. G. de Jong, M. A. Varela, R. M. Schiffelers, S. El Andaloussi, M. J. Wood, P. Vader, Mol. Ther. 2017, 25, 1580.

[32] P. Vader, I. Mager, Y. Lee, J. Z. Nordin, S. E. Andaloussi, M. J. Wood, Methods Mol. Biol. 2017, 1545, 197.

[33] D. Ha, N. Yang, V. Nadithe, Acta Pharm. Sin. B 2016, 6, 287.

[34] L. Kumar, S. Verma, B. Vaidya, V. Gupta, Curr. Pharm. Des. 2015, 21, 4556.

[35] M. V. Lomova, A. I. Brichkina, M. V. Kiryukhin, E. N. Vasina, A. M. Pavlov, D. A. Gorin, G. B. Sukhorukov, M. N. Antipina, ACS Appl. Mater. Interfaces 2015, 7, 11732.

[36] L. J. De Cock, S. De Koker, B. G. De Geest, J. Grooten, C. Vervaet, J. P. Remon, G. B. Sukhorukov, M. N. Antipina, Angew. Chem., Int. Ed. 2010, 49, 6954.

[37] G. B. Sukhorukov, A. L. Rogach, B. Zebli, T. Liedl, A. G. Skirtach, K. Kohler, A. A. Antipov, N. Gaponik, A. S. Susha, M. Winterhalter, W. J. Parak, Small 2005, 1, 194.

[38] L. Kastl, D. Sasse, V. Wulf, R. Hartmann, J. Mircheski, C. Ranke, S. Carregal-Romero, J. A. Martinez-Lopez, R. Fernandez-Chacon, W. J. Parak, H. P. Elsasser, P. Rivera Gil, ACS Nano 2013, 7, 6605.

[39] A. M. Pavlov, A. V. Sapelkin, X. Huang, K. M. Y. P'ng, A. J. Bushby, G. B. Sukhorukov, A. G. Skirtach, Macromol. Biosci. 2011, 11, 848.

[40] J. Rejman, V. Oberle, I. S. Zuhorn, D. Hoekstra, Biochem. J. 2004, $377,159$.

[41] T. Tian, Y. L. Zhu, Y. Y. Zhou, G. F. Liang, Y. Y. Wang, F. H. Hu, Z. D. Xiao, J. Biol. Chem. 2014, 289, 22258.

[42] M. Ishikawa, V. Biju, Prog. Mol. Biol. Transl. Sci. 2011, 104, 53.

[43] Y. F. Tan, R. C. Mundargi, M. H. Chen, J. Lessig, B. Neu, S. S. Venkatraman, T. T. Wong, Small 2014, 10, 1790.

[44] E. Metzger, S. S. Stepputtis, J. Strietz, B. T. Preca, S. Urban, D. Willmann, A. Allen, F. Zenk, N. lovino, P. Bronsert, A. Proske, M. Follo, M. Boerries, E. Stickeler, J. Xu, M. B. Wallace, J. A. Stafford, T. Kanouni, J. Maurer, R. Schule, Cancer Res. 2017, 77, 5900.

[45] F. N. Faruqu, L. Xu, K. T. Al-Jamal, J. Vis. Exp. 2018, 142.

[46] S. Scala, A. Aiuti, Blood Adv. 2019, 3, 1916.

[47] S. F. Martins Gomes, A. J. Westermann, T. Sauerwein, T. Hertlein, K. U. Forstner, K. Ohlsen, M. Metzger, E. V. Shusta, B. J. Kim, A. Appelt-Menzel, A. Schubert-Unkmeir, Front. Microbiol. 2019, 10, 1181.

[48] S. Kohlscheen, H. Bonig, U. Modlich, Hum. Gene Ther. 2017, 28, 782. 
[49] E. P. Papapetrou, N. C. Zoumbos, A. Athanassiadou, Gene Ther 2005, 12, S118.

[50] M. C. Gundry, L. Brunetti, A. Lin, A. E. Mayle, A. Kitano, D. Wagner, J. I. Hsu, K. A. Hoegenauer, C. M. Rooney, M. A. Goodell, D. Nakada, Cell Rep. 2016, 17, 1453.

[51] L. Brunetti, M. C. Gundry, A. Kitano, D. Nakada, M. A. Goodell, J. Vis. Exp. 2018, 134.

[52] R. Kuse, S. Schuster, H. Schubbe, S. Dix, K. Hausmann, Blut 1985 , 50, 243.

[53] D. Y. Gao, Q. Chang, C. Liu, K. Farris, K. Harvey, L. E. McGann, D. English, J. Jansen, J. K. Critser, Cryobiology 1998, 36,40 .
[54] M. M. M. Kakran, W. John Tng, H. Liang, D. B. Trushina, G. Sukhorukov, H. H. Ng, M. N. Antipina, J. Mater. Chem. B 2015, 3, 5842.

[55] A. Wang, Y. Yang, X. Zhang, X. Liu, W. Cui, J. Li, ChemPlusChem 2015.

[56] D. B. Trushina, T. V. Bukreeva, M. N. Antipina, Cryst. Growth Des. 2016, 16, 1311.

[57] S. Q. Tsai, Z. Zheng, N. T. Nguyen, M. Liebers, V. V. Topkar, V. Thapar, N. Wyvekens, C. Khayter, A. J. Iafrate, L. P. Le, M. J. Aryee, J. K. Joung, Nat. Biotechnol. 2015, 33, 187.

[58] C. Mussolino, R. Morbitzer, F. Lutge, N. Dannemann, T. Lahaye, T. Cathomen, Nucleic Acids Res. 2011, 39, 9283. 